\title{
Spatial risk profiling of Plasmodium falciparum parasitaemia in a high endemicity area in Côte d'Ivoire Giovanna Raso*†1,2,3, Kigbafori D Silué ${ }^{\dagger 1,4}$, Penelope Vounatsou ${ }^{3}$, Burton H Singer ${ }^{5}$, Ahoua Yapi ${ }^{4}$, Marcel Tanner ${ }^{3}$, Jürg Utzinger ${ }^{3}$ and Eliézer K N'Goran ${ }^{1,4}$
}

Address: ${ }^{1}$ Département Environnement et Santé, Centre Suisse de Recherches Scientifiques, Abidjan, Côte d'Ivoire, ${ }^{2}$ School of Population Health, University of Queensland, Brisbane, Australia, ${ }^{3}$ Department of Public Health and Epidemiology, Swiss Tropical Institute, Basel, Switzerland, ${ }^{4}$ UFR Biosciences, Université de Cocody-Abidjan, Abidjan, Côte d'Ivoire and ${ }^{5}$ Office of Population Research, Princeton University, Princeton, USA

Email: Giovanna Raso* - giovanna.raso@gmail.com; Kigbafori D Silué - kigbafori.silue@csrs.ci; Penelope Vounatsou - penelope.vounatsou@unibas.ch; Burton H Singer - singer@princeton.edu; Ahoua Yapi - yapiah@yahoo.fr; Marcel Tanner - marcel.tanner@unibas.ch; Jürg Utzinger - juerg.utzinger@unibas.ch; Eliézer K N'Goran - eliezerngoran@yahoo.fr

* Corresponding author †Equal contributors

Published: II November 2009

Malaria Journal 2009, 8:252 doi:10.1186/1475-2875-8-252
Received: 3 August 2009

Accepted: II November 2009

This article is available from: http://www.malariajournal.com/content/8/I/252

(c) 2009 Raso et al; licensee BioMed Central Ltd.

This is an Open Access article distributed under the terms of the Creative Commons Attribution License (http://creativecommons.org/licenses/by/2.0), which permits unrestricted use, distribution, and reproduction in any medium, provided the original work is properly cited.

\begin{abstract}
Background: The objective of this study was to identify demographic, environmental and socioeconomic risk factors and spatial patterns of Plasmodium falciparum parasitaemia in a high endemicity area of Africa, and to specify how this information can facilitate improved malaria control at the district level.

Methods: A questionnaire was administered to about 4,000 schoolchildren in 55 schools in western Côte d'Ivoire to determine children's socioeconomic status and their habit of sleeping under bed nets. Environmental data were obtained from satellite images, digitized ground maps and a second questionnaire addressed to school directors. Finger prick blood samples were collected and $P$. falciparum parasitaemia determined under a microscope using standardized, qualitycontrolled methods. Bayesian variogram models were utilized for spatial risk modelling and mapping of $P$. falciparum parasitaemia at non-sampled locations, assuming stationary and nonstationary underlying spatial dependence.
\end{abstract}

Results: Two-thirds of the schoolchildren were infected with $P$. falciparum and the mean parasitaemia among infected children was 959 parasites/ $\mu$ l of blood. Age, socioeconomic status, not sleeping under a bed net, coverage rate with bed nets and environmental factors (e.g., normalized difference vegetation index, rainfall, land surface temperature and living in close proximity to standing water) were significantly associated with the risk of $P$. falciparum parasitaemia. After accounting for spatial correlation, age, bed net coverage, rainfall during the main malaria transmission season and distance to rivers remained significant covariates.

Conclusion: It is argued that a massive increase in bed net coverage, particularly in villages in close proximity to rivers, in concert with other control measures, is necessary to bring malaria endemicity down to intermediate or low levels. 


\section{Background}

Malaria remains one of the most pressing public health and poverty-related issue in the developing world, particularly in sub-Saharan Africa [1]. Each year, malaria might claim the lives of $>1$ million individuals. There are $>500$ million episodes of clinical Plasmodium falciparum malaria and the global burden might exceed 40 million disabilityadjusted life years (DALYs) [2-4]. Mortality, morbidity and economic losses due to malaria could be reduced significantly if effective measures, such as sleeping under long-lasting insecticidal nets (LLINs) and access to prompt diagnosis and effective treatment using artemisinin-based combination therapy (ACT) were made available to all those in need [5]. Interventions aiming at the control and local elimination of malaria require reliable risk maps in order to enhance the efficacy and cost-effectiveness of control measures. Since parasitaemia is correlated with clinical manifestations of malaria [6], parasitaemia risk maps are a useful tool for the spatial targeting of control interventions. Ongoing blood sampling at the household level on a broad scale is expensive and not practical for surveillance purposes. District-level planning and targeting would be greatly facilitated by rapid and non-invasive identification of high-risk zones.

Over the past decade, geographical information system (GIS) and remote sensing technologies have been widely used for mapping malaria $[1,7,8]$. However, purely GIS and remote sensing approaches have a number of shortcomings, due to their inability to quantify the relation between environmental factors and malaria risk and, consequently, infer predictions from statistical models [9]. Furthermore, classical statistical models have been widely employed to evaluate the relationship between disease risk and demographic, environmental and socioeconomic factors, assuming independence of spatially-explicit data [10-12]. Since disease data cluster in space, the assumption of independence is violated, and hence the statistical significance of the model covariates often overestimated [13]. It follows that predictive risk models lack accuracy.

In recent work by the authors, Bayesian non-stationary geostatistical models were employed for spatial risk profiling of malaria $[9,14,15]$. The strengths of these models are their accountancy for spatial dependence in the data, and the assumption of non-stationary spatial processes. The use of non-stationary models is further justified on the ground that local characteristics related to human behaviour and environment, including vector ecology, depend on location. Consequently, assuming stationarity may provide unreliable results when analyzing spatiallyexplicit disease data.

Here, risk factors and spatial patterns of $P$. falciparum parasitaemia among school-aged children in a high endemic- ity setting of western Côte d'Ivoire are elucidated. An integrated approach, using GIS and remotely-sensed environmental data, questionnaire and parasitological survey data and Bayesian geostatistical models was employed. Finally, the use of non-stationary models for risk profiling of $P$. falciparum parasitaemia at a regional scale was explored. The identified risk factors can help district health planners to implement malaria control interventions in a spatially-explicit manner, followed by monitoring and surveillance so that control tools can be finetuned over time to enhance their performance [16].

\section{Methods}

\section{Study area and population}

This study was carried out in the region of Man, a mountainous area in the western part of Côte d'Ivoire, which is highly endemic for $P$. falciparum malaria, as well as helminth infections [17-21]. Climate conditions are tropical with rains occurring from March to October with highest precipitation observed in July and August. The dry season extends from November to February.

The present study was carried out between October 2001 and February 2002. Schoolchildren from 57 rural schools attending grades 3-5 were invited for finger prick blood samples and two questionnaires were administered, one addressed to schoolchildren and the second one to school directors.

\section{Ethical clearance}

The study protocol was approved by the institutional research commissions of the Swiss Tropical Institute (Basel, Switzerland) and the Centre Suisse de Recherches Scientifiques (Abidjan, Côte d'Ivoire). Ethical clearance was obtained by the Ministry of Health in Côte d'Ivoire.

\section{Cross-sectional surveys}

Thin and thick blood films were prepared from finger prick blood samples on microscope slides, air-dried and transferred to a laboratory in the town of Man. Slides were stained with 10\% Giemsa and examined under a light microscope by experienced laboratory technicians. The number of Plasmodium spp. parasites was counted by assuming a standard white blood cell count of $8,000 / \mu \mathrm{l}$ of blood.

The schoolchildren questionnaire was used to obtain information about assets on ownership and household characteristics (total of 12 indicators), and perceived symptoms and diseases (total of 17 morbidity indicators). In addition, children were asked whether they slept under a bed net and whether they were living in the village of the school or in a nearby village or hamlet. An asset-based approach was used to stratify schoolchildren into five socio-economic groups [19]. 
The questionnaire addressed to school directors included three main topics, i.e., (i) village demographics, (ii) health issues and (iii) local environment (e.g., presence of swamps, irrigation fields and pasture nearby the village and the estimated distances). In case the school directors felt they were not sufficiently acquainted to respond to these questions, they were invited to consult with other village authorities.

\section{Environmental data}

Geographical coordinates for each school were collected using a hand-held Magellan 320 global positioning system (GPS; Thales Navigation, Santa Clara, CA, USA). Distance to rivers was calculated from digitized ground maps. Normalized difference vegetation index (NDVI) and land surface temperature (LST) were downloaded at $1 \times 1 \mathrm{~km}$ spatial resolution from Moderate Resolution Imaging Spectroradiometer (MODIS) from USGS EROS Data Centre. Rainfall estimate (RFE) data with an $8 \times 8 \mathrm{~km}$ spatial resolution from Meteosat 7 satellite were obtained from the Africa Data Dissemination Service (ADDS). NDVI, LST and RFE were downloaded for the period of September 2001 to August 2002 and processed as detailed elsewhere [22]. A digital elevation model (DEM) was employed originating from the Shuttle Radar Topography Mission (SRTM) to delineate watersheds [23].

\section{Data management and analysis}

Data were entered twice and cross-checked. Geographical data were displayed in ArcView GIS version 3.2 (Environmental Systems Research Institute, Inc., Redlands, CA, USA). Schoolchildren were subdivided into two age groups: (i) 6-10 years and (ii) 11-16 years. Bed net coverage was calculated as the percentage of schoolchildren who reported sleeping under a bed net at the unit of the school.

All demographic, environmental and socioeconomic covariates were fitted into negative binomial regression models on the P. falciparum parasitaemia data, using STATA version 9.0 (Stata Corporation, College Station, TX, USA). Covariates with a significance level $<0.15$ were built into three different spatial models for $P$. falciparum parasitaemia using WinBUGS version 1.4 (Imperial College \& Medical Research Council, London, UK). The models were (i) a stationary Bayesian negative binomial regression model, and (ii) two non-stationary Bayesian negative binomial regression models. To take into account the spatial heterogeneity, location-specific random effects were integrated in the logistic models, assuming that they are distributed according to a multivariate normal distribution with variance-covariance matrix related to the variogram of the spatial process. Markov chain Monte Carlo (MCMC) simulation was employed to estimate the model parameters [24]. Model covariates from the final model were utilized to generate a smooth map of $P$. falciparum parasitaemia using Bayesian kriging [25].

\section{Model specification}

To model $P$. falciparum parasitaemia, let $Z_{i j}$ be the $P$. falciparum parasite count in blood films of schoolchild $j$ in village $i$. It was assumed that $Z_{i j}$ arises from a negative binomial distribution, $Z_{i j} \sim N b\left(\mu_{i j}, r\right)$ with mean $\mu_{i j}$ and over-dispersion (extra variation) $r$. The covariates $\underline{X}_{i j}$ and village-specific random effect $\varphi_{i}$ were modeled with $\log \left(\mu_{i j}\right)$ as the outcome, that is $\log \left(\mu_{i j}\right)=\underline{X}_{i j}^{T} \underline{\beta}+\varphi_{i}$, where $\underline{\beta}$ is the vector of regression coefficients. The spatial correlation was introduced on the $\varphi_{i}^{\prime}$ s by assuming that $\underline{\varphi}_{-}=$ $\left(\varphi_{1}, \varphi_{2}, \ldots, \varphi_{N}\right)^{T}$ has a multivariate normal distribution, $\underline{\beta}$ $\sim M V N(\underline{0}, \Sigma)$, with variance-covariance matrix $\Sigma$. Moreover, an isotropic spatial process was assumed, i.e., $\Sigma_{m n}=\sigma^{2}$ $\exp \left(-u d_{m n}\right)$, where $d_{m n}$ is the Euclidean distance between village $m$ and village $n, \sigma^{2}$ is the geographic variability known as the sill, and $u$ is a smoothing parameter that controls the rate of correlation decay with increasing distance. To take into account non-stationarity, the study area was partitioned in $K$ subregions and a local stationary spatial process $\underset{\sim}{\omega_{k}}$ was assumed in each subregion $k=1$, ..., $K$. One type of model included ecological subregions, i.e., watersheds of rivers, whereas the other type included fixed subregions, i.e., the study area was subdivided into two subregions on a diagonal from the north-western corner to the south-eastern corner of the study area. Spatial correlation in the study area was viewed as a mixture of the different spatial processes. The spatial random effect $\varphi_{i}$ at location $i$ was modeled as a weighted average of the subregion-specific (independent) stationary processes as follows: $\phi_{i}=\sum_{k=1}^{K} a_{i k} \omega_{k i}$, with weights $a_{i k^{\prime}}$ which are decreasing functions of the distance between location $i$ and the centroids of the subregions $k$ [26]. Assuming $\underline{\omega}_{k}$ $\sim \operatorname{MVN}\left(0, \Sigma_{k}\right),\left(\Sigma_{k}\right)_{i j}=\sigma_{k}^{2} \operatorname{corr}\left(d_{i j} ; u_{k}\right)$, it follows that $\underline{\phi}=N\left(\underline{0}, \sum_{k=1}^{K} A_{k}^{T} \sum_{k} A_{k}\right)$, with $A_{k}=\operatorname{diag}\left\{a_{1 k^{\prime}} a_{2 k^{\prime}} \ldots, a_{n k}\right\}$. The range is defined as the minimum distance at which spatial correlation between locations is below $5 \%$. It can be calculated as $3 / u_{k}$ and is expressed in meters. 


\section{Model implementation}

Following a Bayesian model specification, prior distributions for the model parameters were adopted. Vague Normal distributions for the $\underline{\beta}$ parameters with large variances (i.e., 10,000), gamma prior for $r$ with large variance, inverse gamma priors for $\sigma_{k}^{2}$ and uniform priors for $u_{k^{\prime}} k$ $=1, \ldots, K$ were chosen. MCMC simulation was employed to estimate the model parameters [24]. A single chain sampler with a burn-in of 5,000 iterations was run. Convergence was assessed by inspection of ergodic averages of selected model parameters. Covariates from the binomial regression models were used to generate a smooth risk map for $P$. falciparum parasitaemia using Bayesian kriging [25].

\section{Model performance and predictive ability}

The deviance information criterion (DIC) was utilized to assess the model performance [27]. Additionally, a twostage approach was adapted for assessment of model performance based on the predictive ability. First, a training sample from the current database was utilized by fitting individual-level data from 43 randomly selected schools into the negative binomial regression models. The individual-level data from the remaining schools were utilized for prediction purposes. 95\%, 75\%, 50\%, 25\% and 1-5\% Bayesian credible intervals (BCIs) of the posterior predictive distribution of test individuals were calculated. The model with the highest percentage of correctly predicted individual parasitaemia within the interval with the smallest coverage was considered as the best predicting one. Second, the predictive ability of the models was assessed using a Bayesian p-value analogue calculated from the predictive posterior distribution, recently presented by Gosoniu and colleagues [9]. The Bayesian pvalue is calculated as $1 / 1000 \sum_{j=1}^{1000} \min \left(I\left(p_{i}^{r e p(j)}>p_{i}^{o b s}\right), I\left(p_{i}^{r e p(j)}<p_{i}^{o b s}\right)\right) . \quad I(\cdot)$ denotes the number of points fulfilling the specific condition in the argument, $p_{i}{ }^{o b s}$ is the observed parasitaemia of an individual and $p_{i}^{\text {rep }}=p_{i}^{\text {rep(1) }}, \ldots, p_{i}^{\text {rep (1000) }}$ are 1,000 replicated data from the predictive distribution for a test individual. When the median of the predictive posterior distribution is close to 0.5 , the model predicts the observed data well. The model with median p-values closest to 0.5 is considered the best performing one.

\section{Results}

\section{Study cohort}

A total of 3,962 schoolchildren had complete data records, i.e., were individually interviewed and had P. fal- ciparum parasitaemia results from blood film examination. There were 2,340 boys (59.1\%) and 1,622 girls $(40.9 \%)$. With regard to age, 1,684 children $(42.5 \%)$ were between 6 and 10 years, whereas 2,278 children $(57.5 \%)$ were aged 11-16 years.

\section{Plasmodium falciparum parasitaemia}

Almost two out of three children were infected with P. falciparum (64.9\%). Other Plasmodium species were rare: Plasmodium malariae and Plasmodium ovale infections were found in $117(3.0 \%)$ and 7 children (0.2\%), respectively. All subsequent analyses focus on $P$. falciparum. At the unit of the school, the prevalence of $P$. falciparum ranged from $34.0 \%$ to $91.9 \%$.

Among $P$. falciparum-infected children, the mean parasitaemia was 959 parasites/ $\mu$ l of blood. Whilst approximately a third of the children had no $P$. falciparum infection as determined by light microscopy, a third of the children had a $P$. falciparum parasitaemia $<500$ parasites/ $\mu \mathrm{l}$ of blood (37.9\%), and one-fourth had a parasitaemia ranging between 500 and 5,000 parasites/ $\mu$ l of blood $(25.1 \%)$. Only $72(1.8 \%)$ of the children had a parasite count $>5,000$ parasites $/ \mu$ l of blood. At the unit of the school, the mean $P$. falciparum parasitaemia ranged from 63 to 2,178 parasites/ $\mu$ l of blood.

\section{Risk profiling and spatial patterns}

Results of the bivariate non-spatial analyses are shown in Table 1 . Children aged 6-10 years were at a significantly higher risk of having a high $P$. falciparum parasitaemia than their older peers. Sex was not significantly associated with $P$. falciparum parasitaemia. Children from the fourth and fifth quintile (the less poor and least poor) were at a higher risk of having higher parasitaemia levels compared to the poorest schoolchildren. Other significant risk factors included not sleeping under a bed net, bed net coverage at the unit of school, NDVI, RFE, LST, close proximity to standing water (rivers, swamps and irrigated fields) and absence of pasture near villages. There was no significant association between $P$. falciparum parasitaemia and distance to the closest health care facility. Finally, no significant association was found between $P$. falciparum parasitaemia and the children's place of residence (living in the same village as the school or in a nearby village or hamlet).

The mean $P$. falciparum parasitaemia at the unit of the school is shown in Figure 1. Three schools in the northeastern part of the study area and one in the central part had a mean parasitaemia $>1,500$ parasites $/ \mu$ l of blood.

\section{Spatial analyses and model performance}

Results of the spatial analyses are summarized in Table 2. Children's age, bed net coverage and mean RFE during the 
Table I: Results of the bivariate negative binomial regression models for $P$. falciparum parasitaemia among 3,962 schoolchildren from 55 rural schools of western Côte d'Ivoire.

\begin{tabular}{|c|c|c|c|c|}
\hline \multirow[t]{2}{*}{ Source of data } & \multirow[t]{2}{*}{ Indicator } & \multicolumn{3}{|c|}{ Plasmodium falciparum parasitaemia } \\
\hline & & IRR $^{\mathbf{a}}$ & $95 \% \mathrm{Cl}^{\mathrm{b}}$ & $P$-value (AICc) \\
\hline \multirow[t]{3}{*}{ School registry } & Age & & & \\
\hline & 6-10 years & 1.00 & & \\
\hline & $11-16$ years & 0.70 & $0.60,0.83$ & $<0.001$ \\
\hline \multirow[t]{11}{*}{ Questionnaire addressed to schoolchildren } & Socioeconomic status & & & \\
\hline & Most poor & 1.00 & & \\
\hline & Very poor & 1.02 & $0.79,1.32$ & \\
\hline & Poor & 0.93 & $0.72,1.20$ & \\
\hline & Less poor & 1.34 & $1.04,1.73$ & \\
\hline & Least poor & 1.34 & $1.04,1.73$ & 0.005 \\
\hline & Sleeping under a bed net & 0.75 & $0.58,0.98$ & 0.040 \\
\hline & Bed net coverage & & & \\
\hline & $<25 \%$ & 1.00 & & \\
\hline & $\geq 25 \%$ & 0.38 & $0.28,0.53$ & $<0.001$ \\
\hline & Living in the same village as school & 0.86 & $0.70,1.06$ & 0.162 \\
\hline Health district registry & Distance to health care facility & 1.00 & $0.93,1.08$ & 0.916 \\
\hline \multirow[t]{6}{*}{ Questionnaire addressed to school directors } & Presence of swamps for rice cultivation & 0.85 & $0.72,1.01$ & 0.124 \\
\hline & Distance to irrigated field & & & \\
\hline & $<500 \mathrm{~m}$ & 1.00 & & \\
\hline & $500-999 \mathrm{~m}$ & 0.55 & $0.32,0.96$ & \\
\hline & $\geq 1000 \mathrm{~m}$ & 0.86 & $0.59,1.22$ & 0.117 \\
\hline & Presence of pasture & 0.77 & $0.62,0.96$ & 0.022 \\
\hline \multirow[t]{17}{*}{ Satellite images } & NDVI & & & \\
\hline & Mean $§ \S$ & 1.03 & $0.94,1.12$ & $0.532(46,255)$ \\
\hline & Mean IIT & 1.06 & $0.97,1.15$ & $0.177(46,253)$ \\
\hline & Mean IIIII & 0.95 & $0.88,1.03$ & $0.205(46,254)$ \\
\hline & Annual mean & 1.00 & $0.92,1.08$ & $0.950(46,255)$ \\
\hline & Mean of the transmission season & 1.14 & $1.05,1.23$ & $0.001(46,245)$ \\
\hline & Annual mean NDVI (categorized) & & & \\
\hline & $<0.65$ & 1.00 & & \\
\hline & $0.65-0.70$ & 1.66 & $1.30,2.12$ & \\
\hline & $>0.70$ & 1.31 & $1.05,1.64$ & $<0.001(46,240)$ \\
\hline & RFE & & & \\
\hline & Mean Id & 1.06 & $0.98,1.15$ & $0.122(46,253)$ \\
\hline & Mean IIe & 1.01 & $0.94,1.09$ & $0.742(46,255)$ \\
\hline & Mean IIIf & 1.11 & $1.02,1.20$ & $0.015(46,249)$ \\
\hline & Sum of annual rainfall & 1.17 & $1.08,1.26$ & $<0.001(46,238)$ \\
\hline & Mean of the transmission seasong & 1.22 & $1.13,1.32$ & $<0.001(46,230)$ \\
\hline & Maximum LST & 1.09 & $1.00,1.18$ & 0.048 \\
\hline \multirow[t]{5}{*}{ Digitized ground maps } & Distance to rivers & 0.85 & $0.78,0.92$ & $<0.00 \mathrm{I}(46,24 \mathrm{I})$ \\
\hline & Distance to rivers (categorized) & & & \\
\hline & $<500 \mathrm{~m}$ & 1.00 & & \\
\hline & $500-999 \mathrm{~m}$ & 0.98 & $0.80,1.21$ & \\
\hline & $\geq 1000 \mathrm{~m}$ & 0.62 & $0.5 \mathrm{I}, 0.76$ & $<0.001(46,236)$ \\
\hline
\end{tabular}

aIRR: incidence-rate ratio; ${ }^{b} \mathrm{Cl}$ : confidence interval; ${ }^{\mathrm{A}} \mathrm{AIC}$ : Akaike information criterion; dMean I: mean value during the month prior to blood sample collection; eMean II: mean value during the month of collection and the previous month; Pean III: mean value during the month of collection and the two previous months; gThe transmission season is during June to August

main malaria transmission season (June to August) were significant covariates in the stationary negative binomial regression model. The three covariates were also found significant in the non-stationary model with ecological subregions. In contrast, mean RFE during the transmission season was not significant in the negative binomial regression model with fixed subregions. In the latter model, age, bed net coverage and distance to rivers were significant covariates. There was a clear over-dispersion $(r$ $=0.16$ ) of the data. The range where spatial correlation is below $5 \%$ was $1.9 \mathrm{~km}$ in the stationary model. For the non-stationary model with ecological subregions, the ranges were $2.3 \mathrm{~km}, 1.9 \mathrm{~km}$ and $2.1 \mathrm{~km}$, respectively. For the non-stationary model with fixed subregions, the 


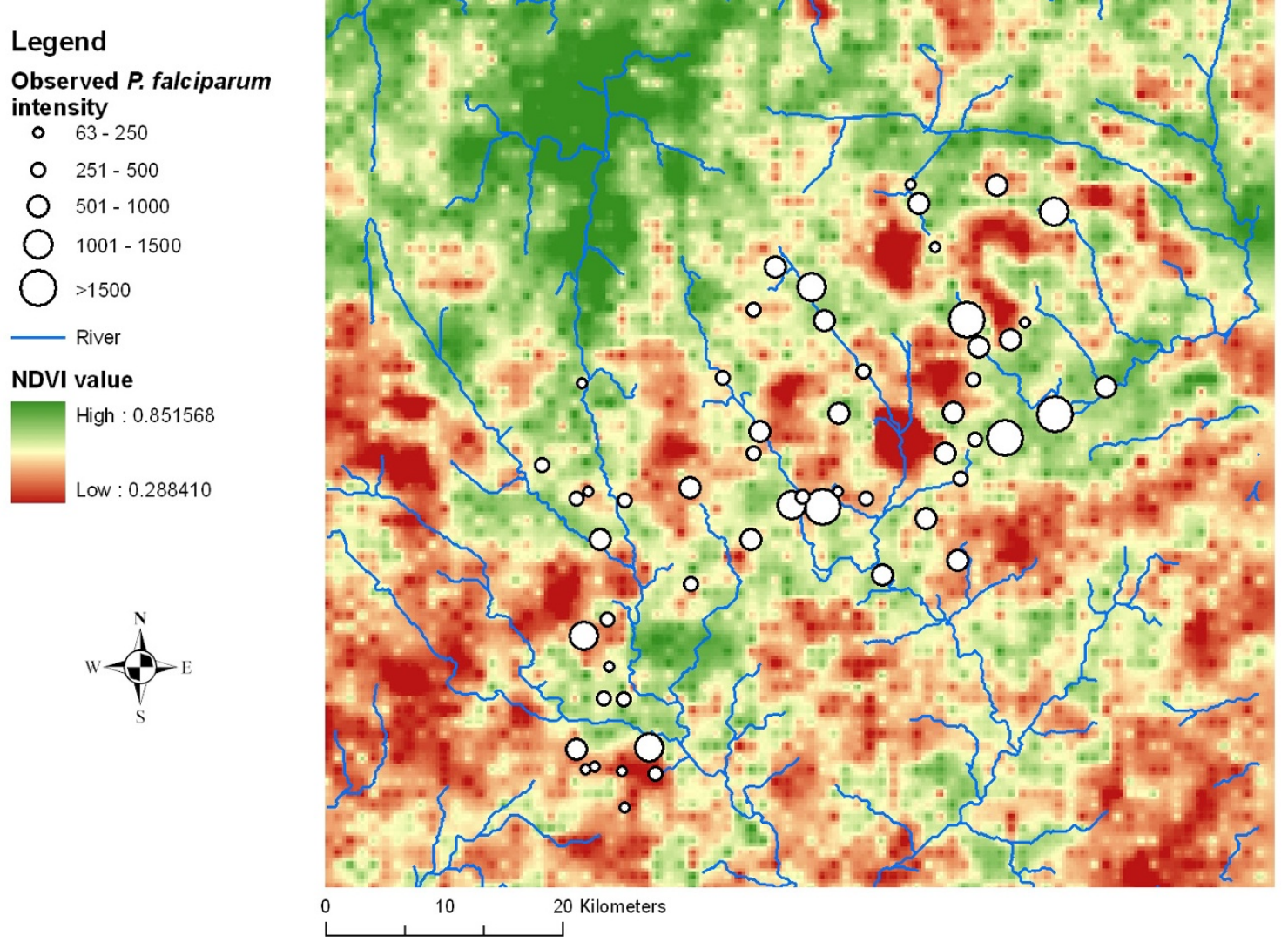

Figure I

Mean $P$. falciparum parasitaemia among 3,962 schoolchildren from 55 sampled schools in the region of Man, western Côte d'Ivoire during the school year 200I/2002. The normalized difference vegetation index (NDVI) is displayed in the background.

ranges were $1.9 \mathrm{~km}$ and $2.3 \mathrm{~km}$. Geographical variability differed depending on the subregion in the non-stationary model with ecological subregions.

For the assessment of the model performance, the spatial models without the covariates bed net coverage, presence of swamps, distance to irrigated fields and presence of pasture were used, since no information was available for prediction. Results of the spatial analyses of those models are shown in Table 3. The differences between DICs for the three models were only marginal, and hence the results suggest that the stationary and the non-stationary models performed similarly. Table 4 summarizes the results of the models' predictive ability using different BCIs. Virtually no difference was found between the stationary and the non-stationary models, although the latter type of models seemed to perform slightly better at the smallest BCIs. The $\mathrm{p}$-values calculated from the predictive distribution of the 1,034 selected individuals for model validation revealed similar distributions for all three models, including medi- ans, suggesting that the models had the same predictive ability.

\section{Risk mapping}

Figures 2, 3, 4, 5, 6 and 7 display the results from the three stationary and non-stationary $P$. falciparum parasitaemia models. The maps were based on models without the covariates bed net coverage, presence of swamps, distance to irrigated fields and presence of pasture, as this information was missing for prediction. There is a clear difference in the parasitaemia predictions between stationary and non-stationary models. In the non-stationary map inferred from the non-stationary model with ecological subregions, the predicted parasitaemia was considerably higher in the north-eastern part of the study area compared to the maps derived from the stationary model and the non-stationary model with fixed subregions. However, the standard deviations of the predicted parasitaemia inferred from the non-stationary model with ecological subregions show that in this area the prediction 
Table 2: Multivariate stationary and non-stationary spatial analyses results for $P$. falciparum parasitaemia for the region of Man, western Côte d'Ivoire.

\begin{tabular}{|c|c|c|c|c|c|c|}
\hline \multirow[t]{3}{*}{ Indicator } & \multicolumn{6}{|c|}{ Bayesian negative binomial regression models } \\
\hline & \multicolumn{2}{|c|}{ Stationary } & \multicolumn{2}{|c|}{$\begin{array}{l}\text { Non-stationary with ecological } \\
\text { subregions }\end{array}$} & \multicolumn{2}{|c|}{ Non-stationary with fixed subregions } \\
\hline & $\mathbf{I R R}^{\mathbf{a}}$ & $95 \% \mathrm{BCl}$ & IRR $\mathbf{a}$ & $95 \% \mathrm{BClb}$ & $\mathbf{I R R}^{\mathbf{a}}$ & $95 \% \mathrm{BCl}^{\mathrm{b}}$ \\
\hline \multicolumn{7}{|l|}{ Age (years) } \\
\hline $6-10$ & 1.00 & & 1.00 & & 1.00 & \\
\hline $11-16$ & 0.72 & $0.60,0.85$ & 0.71 & $0.60,0.83$ & 0.71 & $0.59,0.83$ \\
\hline \multicolumn{7}{|l|}{ Socioeconomic status } \\
\hline Most poor & 1.00 & & 1.00 & & 1.00 & \\
\hline Very poor & 1.02 & $0.77,1.33$ & 1.00 & $0.75,1.29$ & 1.01 & $0.77,1.30$ \\
\hline Poor & 0.97 & $0.74,1.26$ & 0.96 & $0.73,1.24$ & 0.97 & $0.74,1.25$ \\
\hline Less poor & 1.14 & $0.85,1.51$ & 1.09 & $0.82,1.43$ & 1.10 & $0.83,1.43$ \\
\hline Least poor & 1.08 & $0.79,1.44$ & 1.04 & $0.76,1.39$ & 1.03 & $0.76,1.37$ \\
\hline $\begin{array}{l}\text { Sleeping under a bed } \\
\text { net }\end{array}$ & 0.86 & $0.63,1.14$ & 0.88 & $0.65,1.17$ & 0.87 & $0.65,1.16$ \\
\hline \multicolumn{7}{|l|}{ Bed net coverage $(\%)$} \\
\hline$<25$ & 1.00 & & 1.00 & & 1.00 & \\
\hline$\geq 25$ & 0.51 & $0.24,0.98$ & 0.49 & $0.27,0.82$ & 0.50 & $0.26,0.90$ \\
\hline $\begin{array}{l}\text { Presence of swamps } \\
\text { for rice cultivation }\end{array}$ & 1.11 & $0.7 \mathrm{I}, 1.63$ & 1.23 & $0.80,1.77$ & 1.13 & $0.73,1.67$ \\
\hline \multicolumn{7}{|l|}{$\begin{array}{l}\text { Distance to irrigated } \\
\text { field }(m)\end{array}$} \\
\hline$<500$ & 1.00 & & 1.00 & & 1.00 & \\
\hline $500-999$ & 0.74 & $0.17,2.23$ & 0.66 & $0.23,1.48$ & 0.64 & $0.21,1.59$ \\
\hline$\geq 1000$ & 0.92 & $0.35,2.14$ & 0.95 & $0.47,1.74$ & 0.89 & $0.39,1.76$ \\
\hline Presence of pasture & 0.99 & $0.57,1.59$ & 0.88 & $0.57,1.32$ & 0.92 & $0.58,1.43$ \\
\hline \multicolumn{7}{|l|}{ NDVI (categorized) } \\
\hline$<0.65$ & 1.00 & & 1.00 & & 1.00 & \\
\hline $0.65-0.70$ & 1.42 & $0.8 \mathrm{I}, 2.43$ & 1.57 & $0.95,2.40$ & 1.61 & $0.97,2.49$ \\
\hline$>0.70$ & 0.76 & $0.42,1.33$ & 0.78 & $0.46,1.24$ & 0.78 & $0.46,1.24$ \\
\hline $\begin{array}{l}\text { Mean rainfall during } \\
\text { transmission season }\end{array}$ & 1.28 & $1.00,1.61$ & 1.24 & $1.01,1.51$ & 1.20 & $0.95 \quad 1.54$ \\
\hline Maximum LST & 0.93 & $0.75,1.15$ & 0.95 & $0.76,1.15$ & 0.93 & $0.72,1.16$ \\
\hline \multicolumn{7}{|c|}{ Distance to rivers $(m)$} \\
\hline$<500$ & 1.00 & & 1.00 & & 1.00 & \\
\hline $500-999$ & 1.13 & $0.68,1.74$ & 1.08 & $0.73,1.56$ & 1.03 & $0.66,1.56$ \\
\hline$\geq 1000$ & 0.72 & $0.44,1.09$ & 0.71 & $0.46,1.08$ & 0.63 & $0.42,0.94$ \\
\hline$r^{c}$ & 0.16 & $0.16,0.17$ & 0.16 & $0.16,0.17$ & 0.16 & $0.16,0.17$ \\
\hline$\rho_{1}^{\mathrm{d}}$ & 0.0016 & $0.0005,0.003$ & 0.0014 & $0.0002,0.002$ & 0.0013 & $0.0002,0.002$ \\
\hline$\rho_{2}$ & & & 0.0016 & $0.0005,0.003$ & 0.0016 & $0.0005,0.003$ \\
\hline$\rho_{3}$ & & & 0.0013 & $0.0002,0.002$ & & \\
\hline$\sigma_{1}^{2 e}$ & 0.33 & $0.17,0.57$ & 0.14 & $0.02,0.39$ & 0.13 & $0.02,0.39$ \\
\hline$\sigma_{2}^{2}$ & & & 1.20 & $0.40,3.08$ & 0.58 & $0.26,1.16$ \\
\hline$\sigma_{3}^{2}$ & & & 0.21 & $0.03,0.60$ & & \\
\hline DICf & $46,047.4$ & & $46,044.9$ & & 46,045 & \\
\hline
\end{tabular}

aIRR: incidence-rate ratio; ${ }^{b B C l}$ : Bayesian credible interval; ${ }^{c} r$ : over-dispersion parameter; ${ }^{d} \rho$ : scalar parameter representing the rate of decline of correlation with distance between points; ${ }^{\mathrm{e}} \sigma^{2}$ : estimate of geographic variability; fDIC: deviance information criterion; a composite measure of how well the model does, i.e. a compromise between fit and complexity, with smaller DICs indicating better performance of the model.

error is highest. Nonetheless, all three standard deviation maps show increased standard errors in the north-eastern part of the Man area in western Côte d'Ivoire.

\section{Discussion}

Current anti-malarial prophylaxis and treatment, and vector control using insecticides are susceptible to the emergence of resistant malarial parasites and vectors. Hence, there is a pressing need for other interventions incorporated into the programme that can delay the onset of 
Table 3: Multivariate stationary and non-stationary spatial analyses results for $P$. falciparum parasitaemia for the region of Man, western Côte d'Ivoire.

\begin{tabular}{|c|c|c|c|c|c|c|}
\hline \multirow[t]{3}{*}{ Indicator } & \multicolumn{6}{|c|}{ Bayesian negative binomial regression models } \\
\hline & \multicolumn{2}{|c|}{ Stationary } & \multicolumn{2}{|c|}{$\begin{array}{l}\text { Non-stationary with ecological sub- } \\
\text { regions }\end{array}$} & \multicolumn{2}{|c|}{$\begin{array}{l}\text { Non-stationary with fixed sub- } \\
\text { regions }\end{array}$} \\
\hline & IRR $^{\mathbf{a}}$ & $95 \% \mathrm{BCl}^{\mathrm{b}}$ & IRRa & $95 \% \mathrm{BClb}$ & IRR $^{\mathbf{a}}$ & $95 \% \mathrm{BCl}$ \\
\hline \multicolumn{7}{|l|}{ Age (years) } \\
\hline $6-10$ & 1.00 & & 1.00 & & 1.00 & \\
\hline $11-16$ & 0.72 & $0.60,0.85$ & 0.71 & $0.60,0.83$ & 0.71 & $0.59,0.83$ \\
\hline \multicolumn{7}{|l|}{ Socioeconomic status } \\
\hline Most poor & 1.00 & & 1.00 & & 1.00 & \\
\hline Very poor & 1.02 & $0.77,1.33$ & 1.00 & $0.75,1.30$ & 1.00 & $0.76,1.23$ \\
\hline Poor & 0.98 & $0.74,1.27$ & 0.96 & $0.73,1.25$ & 0.96 & $0.73,1.22$ \\
\hline Less poor & 1.15 & $0.87,1.52$ & 1.11 & $0.84,1.46$ & 1.11 & $0.83,1.44$ \\
\hline Least poor & 1.09 & $0.80,1.46$ & 1.07 & $0.79,1.42$ & 1.05 & $0.77,1.39$ \\
\hline $\begin{array}{l}\text { Sleeping under a bed } \\
\text { net }\end{array}$ & 0.81 & $0.60,1.07$ & 0.81 & $0.61,1.07$ & 0.82 & $0.61,1.08$ \\
\hline \multicolumn{7}{|l|}{ NDVI (categorized) } \\
\hline$<0.65$ & 1.00 & & 1.00 & & 1.00 & \\
\hline $0.65-0.70$ & 1.44 & $0.84,2.35$ & 1.54 & $0.94,2.36$ & 1.69 & $1.04,2.54$ \\
\hline$>0.70$ & 0.77 & $0.43,1.29$ & 0.76 & $0.46,1.19$ & 0.78 & $0.49,1.21$ \\
\hline $\begin{array}{l}\text { Mean rainfall during } \\
\text { transmission season }\end{array}$ & 1.27 & $1.03,1.56$ & 1.25 & $1.00,1.54$ & 1.20 & $0.96,1.51$ \\
\hline Maximum LST & 0.92 & $0.75,1.12$ & 0.91 & $0.75,1.10$ & 0.89 & $0.72,1.09$ \\
\hline \multicolumn{7}{|l|}{ Distance to rivers $(\mathrm{m})$} \\
\hline$<500$ & 1.00 & & 1.00 & & 1.00 & \\
\hline $500-999$ & 1.19 & $0.76,1.80$ & 1.08 & $0.73,1.56$ & 1.01 & $0.98,1.55$ \\
\hline$\geq 1000$ & 0.73 & $0.46,1.10$ & 0.71 & $0.46,1.08$ & 0.61 & $0.39,0.92$ \\
\hline$r^{c}$ & 0.16 & $0.15,0.17$ & 0.16 & $0.15,0.17$ & 0.16 & $0.15,0.17$ \\
\hline$\rho_{1}^{\mathrm{d}}$ & 0.0016 & $0.0005,0.002$ & 0.0013 & $0.0002,0.002$ & 0.0014 & $0.0003,0.003$ \\
\hline$\rho_{2}$ & & & 0.0016 & $0.0005,0.002$ & 0.0016 & $0.0006,0.003$ \\
\hline$\rho_{3}$ & & & 0.0014 & $0.0002,0.002$ & & \\
\hline$\sigma_{1}^{2 e}$ & 0.33 & $0.18,0.54$ & 0.18 & $0.03,0.45$ & 0.14 & $0.02,0.37$ \\
\hline$\sigma_{2}^{2}$ & & & 1.08 & $0.37,2.73$ & 0.60 & $0.27,1.19$ \\
\hline$\sigma_{3}^{2}$ & & & 0.26 & $0.06,0.68$ & & \\
\hline DICf & $46,046.4$ & & $46,044.6$ & & 46,045 & \\
\hline
\end{tabular}

These models were used for calculation of model performance and prediction.

aIRR: incidence-rate ratio; ${ }^{\mathrm{b}} \mathrm{BCl}$ : Bayesian credible interval; ${ }^{\mathrm{c}} r$ : over-dispersion parameter; $\mathrm{d} \rho$ : scalar parameter representing the rate of decline of correlation with distance between points; ${ }^{\mathrm{e}} \sigma^{2}$ : estimate of geographic variability; fDIC: deviance information criterion; a composite measure of how well the model does, i.e. a compromise between fit and complexity, with smaller DICs indicating better performance of the model.

resistance. There is also a need for new drugs and insecticides and a malaria vaccine, coupled with improved monitoring and surveillance [28]. Mapping areas where people are at an elevated risk of infection and $P$. falciparum parasitaemia is important for the design and implementation of district-based malaria control interventions.

Here an integrated approach for spatial risk profiling of $P$. falciparum parasitaemia was used, building on previous research pertaining to the mapping and prediction of helminth infections in the Man region, western Côte d'Ivoire [29]. Reasons why this approach is termed 'integrated' are as follows. First, a diversity of data (demographic, environmental and socioeconomic) was obtained from different sources, including cross-sectional questionnaire and epidemiological surveys and remote sensing. Second, data covered different spatial scales. For example, RFE, LST and NDVI data were collected by remote sensing at a large spatial scale. At a small spatial scale, data on proximity to standing water (e.g., swamps and irrigated agricultural fields) were obtained from questionnaires addressed to school directors and from digitized maps. Third, the data were collated, stored and managed using a GIS. Finally, Bayesian geostatistical models were employed to produce smoothed risk maps of $P$. falciparum parasitaemia, and to compare model outcomes assuming either stationary or non-stationary dependence. Age, socioeconomic status, sleeping under a bed net, bed net coverage and different environmental factors - both small-scale (e.g., close proximity to standing 
Table 4: Percentage of test individuals with $P$. falciparum parasitaemia falling within selected Bayesian credible intervals (BCls).

\begin{tabular}{|c|c|c|c|}
\hline \multirow[t]{2}{*}{ BCls } & \multicolumn{3}{|c|}{ Bayesian negative binomial regression model } \\
\hline & Stationary & Non-stationary (ecological subregions) & Non-stationary (fixed subregions) \\
\hline $95 \%$ & $99 \%$ & $99 \%$ & $99 \%$ \\
\hline $75 \%$ & $94 \%$ & $93 \%$ & $93 \%$ \\
\hline $50 \%$ & $63 \%$ & $63 \%$ & $64 \%$ \\
\hline $25 \%$ & $14 \%$ & $13 \%$ & $13 \%$ \\
\hline $5 \%$ & $2 \%$ & $1 \%$ & $2 \%$ \\
\hline $4 \%$ & $1 \%$ & $1 \%$ & $1 \%$ \\
\hline $3 \%$ & $1 \%$ & $1 \%$ & $1 \%$ \\
\hline $2 \%$ & $1 \%$ & $1 \%$ & $1 \%$ \\
\hline $1 \%$ & $0 \%$ & $0 \%$ & $0 \%$ \\
\hline
\end{tabular}

water) and large-scale (e.g., LST, NDVI and RFE) - were significant risk factors for $P$. falciparum parasitaemia. Interestingly, after introducing spatial correlation into the regression analyses, age, bed net coverage and - depending on the type of the model - mean RFE over the malaria transmission season, and distance to rivers appeared to be significant risk factors for $P$. falciparum parasitaemia. Appraisal of model performance revealed no difference when comparing stationary with non-stationary models. However, the non-stationary model with ecological subregions showed that the geographical variability is different between subregions.

Two shortcomings of the present study should be noted. First, school-aged children are usually not the most severely affected group with malaria in highly endemic
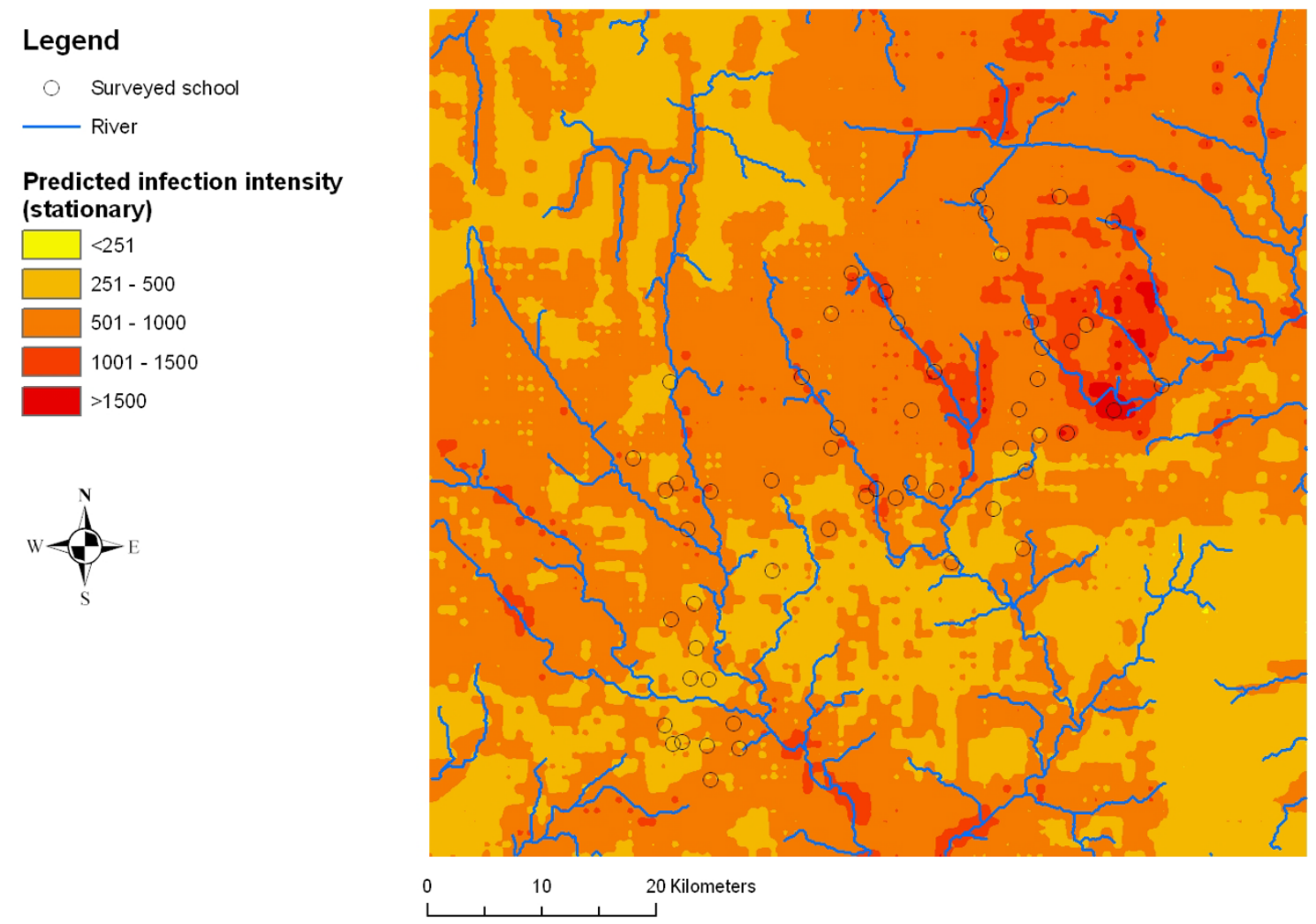

Figure 2

Smoothed map of $P$. falciparum parasitaemia derived from a stationary negative binomial regression model using Bayesian in the region of Man, western Côte d'Ivoire. 

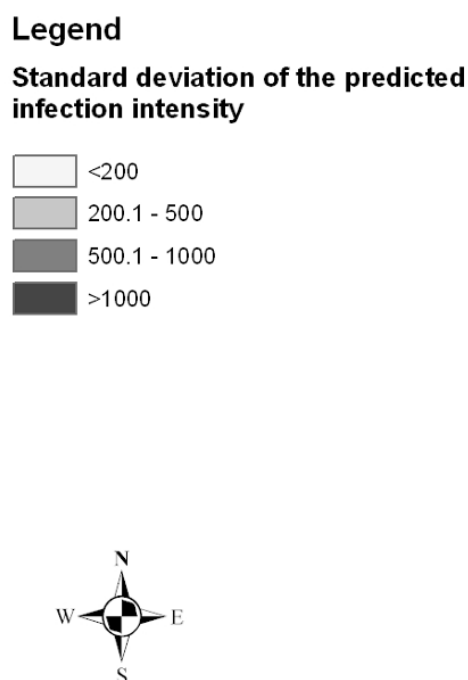

Figure 3

Standard deviation map of the predicted $P$. falciparum parasitaemia derived from a stationary negative binomial regression model using Bayesian kriging in the region of Man, western Côte d'Ivoire.

areas. Since the western part of Côte d'Ivoire is holoendemic for malaria $[15,17,18,21]$, it is likely that schoolaged children have acquired some kind of immunity to malarial parasites [30,31]. However, parasitaemia levels in school-aged children might be higher than in younger children. Underlying reasons are that school-aged children in high endemicity areas are mainly asymptomatic carriers, they might be more exposed to mosquito bites due to their behaviour, they are less likely to be treated because of a lower incidence of clinical malaria, and hence they might harbour considerably more parasites than preschool-aged children. Second, due to the possibility of sequestration mechanisms of infected erythrocytes from peripheral blood, as well as partially acquired immunity, microscopic examination of only a single finger prick blood sample might have underestimated the true prevalence of infection, and $P$. falciparum parasitaemia might have been slightly different [32-34].

Notwithstanding these shortcomings, several risk factors were found to be associated with $P$. falciparum parasitaemia, including demographic factors (e.g., age), socioeconomic factors, personal preventive measures (e.g., sleeping under a bed net and bed net coverage) and a host of environmental factors. As expected, children who reported sleeping under a bed net were less likely to have a high malaria parasitaemia as were children from schools with a bed net coverage $>25 \%$. A study from rural Tanzania revealed that people from poorer households were less likely to access preventive measures [35]. A similar result has been reported for the population under study here [19]. Based on these observations and the common belief that the poorest population segments would share the highest burden of malaria, the current results surprisingly point in the opposite direction: schoolchildren from better-off households were more likely to have a higher parasitaemia than their poorer peers. This result is in accordance with previous work focusing on spatial risk profiles of $P$. falciparum prevalence in the same group of children [15] and consequently warrants further investigation.

For the current mapping of $P$. falciparum parasitaemia, a similar geostatistical approach was used as before when modeling $P$. falciparum prevalence data [15] and common helminth infections $[22,23,36]$. Importantly, the statisti- 

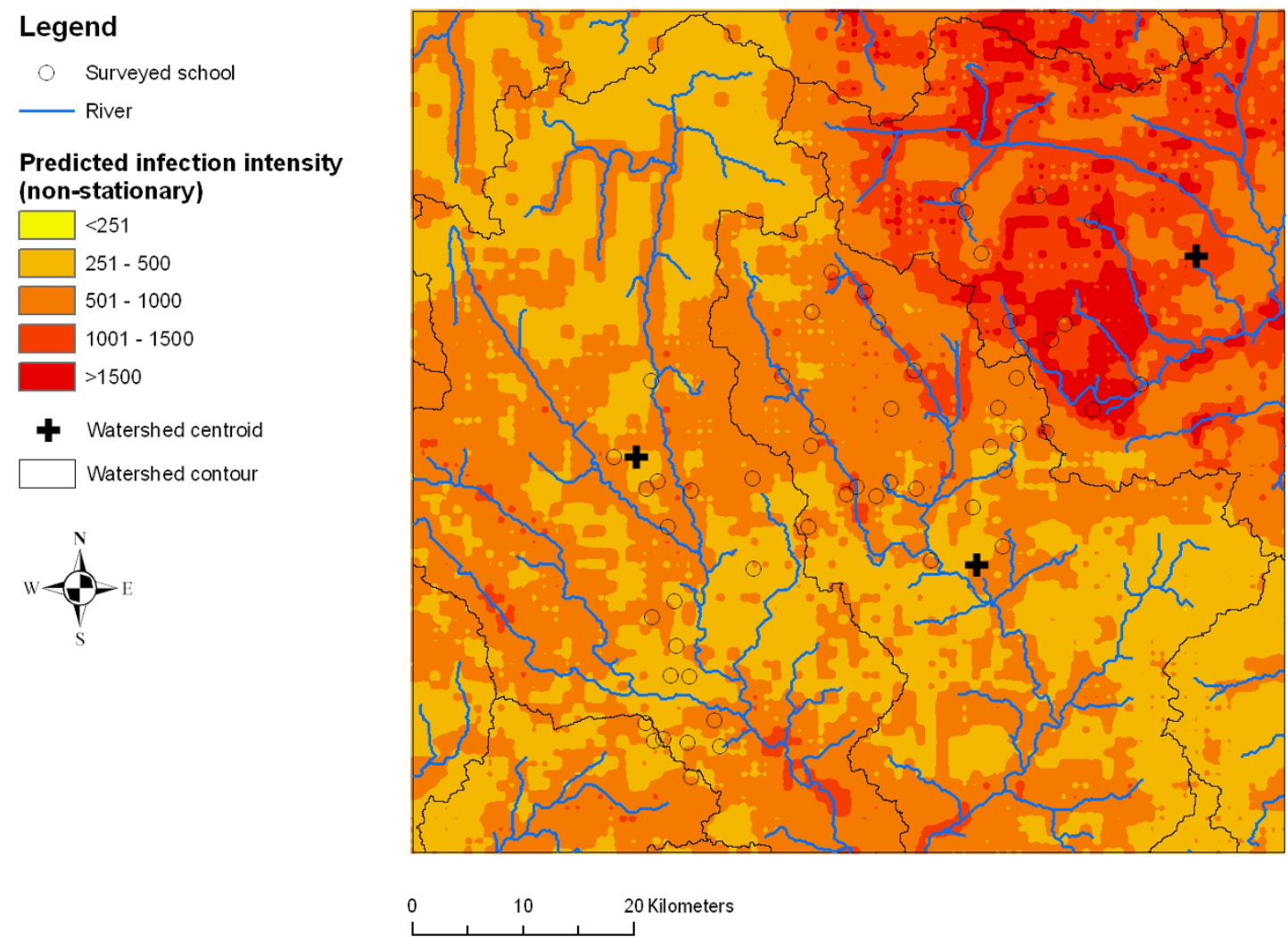

Figure 4

Smoothed map of $P$. falciparum parasitaemia derived from a non-stationary negative binomial regression model with ecologic subregions using Bayesian kriging in the region of Man, western Côte d'Ivoire.

cal significance of several covariates changed once spatial correlation had been taken into account. For example, children's socioeconomic status, sleeping under a bed net and several environmental factors - most notably LST, NDVI, close proximity to standing water and presence of pasture - were not significant anymore in the spatial models. This issue might be explained because omission of spatial correlation, when analysing spatially-explicit data, overestimates the significance of the regression coefficients [13]. In contrast to previous spatial analyses of $P$. falciparum prevalence data, it was found that environmental factors such as rainfall during the main malaria transmission season and distance to the nearest permanent river were significant predictors for $P$. falciparum parasitaemia. These environmental covariates are related to the presence and abundance of malaria vectors, including Anopheles gambiae and Anopheles funestus, which are the key vector species as found in previous work in the nearby forest and wet Savannah zones of Côte d'Ivoire $[37,38]$ and the medium-sized town of Man located in the centre of the current study area [20]. As shown in a study from Burkina Faso these vectors breed in small pools (An. gambiae) and larger semi-permanent water bodies (An. funes- tus) [39]. In previous research pertaining to $P$. falciparum prevalence data, most of the environmental factors included had a large spatial scale and none of the environmental covariates was found significant [15]. Hence, it was concluded that environmental data at a small spatial scale are necessary for more precise spatial risk profiling at the district level where decisions are usually made for the control of malaria and other infectious diseases. Indeed, including information obtained from interviewing the directors of schools about the proximity of residential houses to standing water revealed a number of significant environmental covariates in the non-spatial analyses, although there was a lack of statistical significance in the spatial models. At a more local or regional scale, only distance to rivers, which was used as a proxy for standing water, was significant in one of the spatially-explicit models. Further ground-based investigations are required, since only data derived from questionnaires and digitized maps were used rather than ecological surveys to explore small-scale environmental features. It will also be interesting to determine the use of topography-derived wetness indices, which have been linked to household malaria risk at small spatial scale in two communities in the Kenyan 
Legend
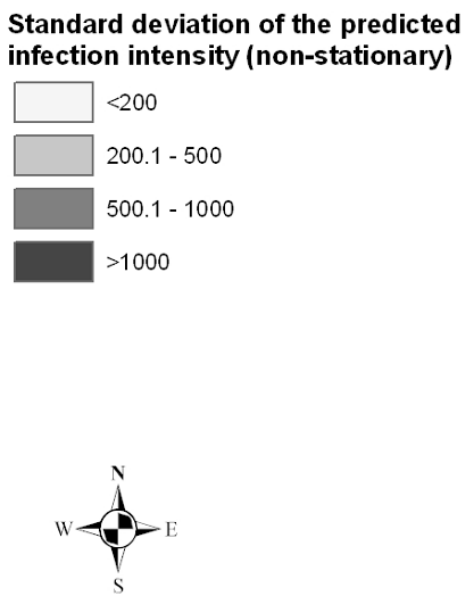
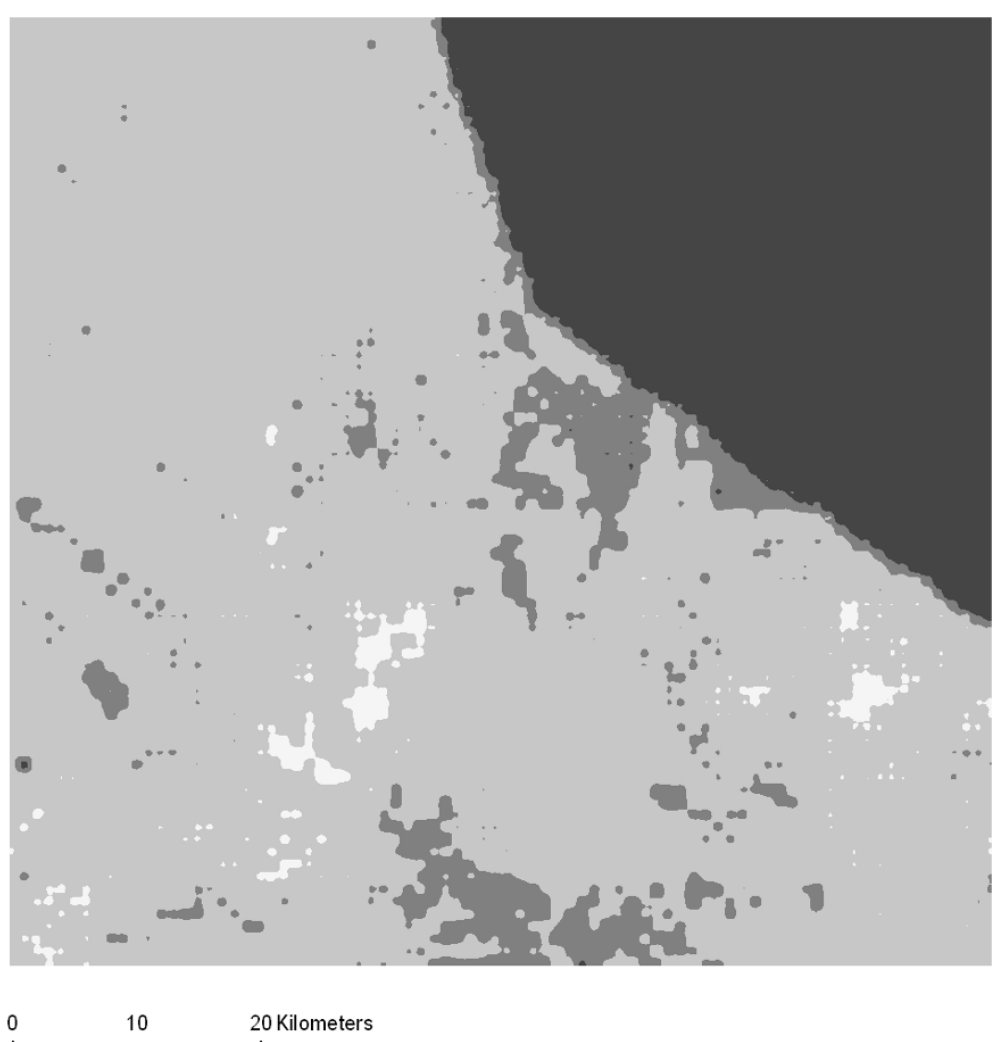

\section{Figure 5}

Standard deviation map of the predicted $P$. falciparum parasitaemia derived from a non-stationary negative binomial regression model with ecologic subregions using Bayesian kriging in the region of Man, western Côte d'Ivoire.

highlands [40]. Perhaps somewhat surprising at first, the present spatial analyses showed that RFE during the main malaria transmission season, which is rather a broad scale indicator, indicated the spatial heterogeneity of parasitaemia in the study area. This observation might be explained by the distinct climatic conditions, i.e., higher precipitation in the mountainous northern part of the study area.

Comparing the performance of different models did not reveal any significant difference in the predictive ability between stationary and non-stationary models, and hence the predicted parasitaemia risk maps were similar. Interestingly though, the non-stationary model with ecological subregions predicted a slightly larger area with high parasitaemia in the north-eastern part of the study area. The corresponding standard deviations of the map showed that uncertainty was particularly high in this subregion. A likely explanation of this observation is that there were fewer sampled locations in that specific subregion (Figure $1)$. However, uncertainty in the north-eastern part of the study area was also elevated (though to a lesser extent) when employing a stationary and a non-stationary model with fixed subregions. Of note, the spatial parameters in the non-stationary model with ecologic subregions revealed that geographic variability differed between subregions. Consequently, this would rule in favour of using non-stationary models for predicting $P$. falciparum parasitaemia. Previous spatial analyses of $P$. falciparum prevalence in the same area revealed that non-stationary models performed somewhat better than stationary models [15].

An important aspect of the current study is that the statistical model approach influences not only the spatial parameter estimates, including the prediction maps and standard deviations of the prediction, but also the significance of malaria risk indicators. Depending on the statistical model chosen, i.e., stationary or non-stationary, the significance of several environmental factors changed. For example, in the stationary and the non-stationary models with ecological subregions, mean RFE during the main malaria transmission season was significantly explaining the geographical heterogeneity, whereas in the non-sta- 

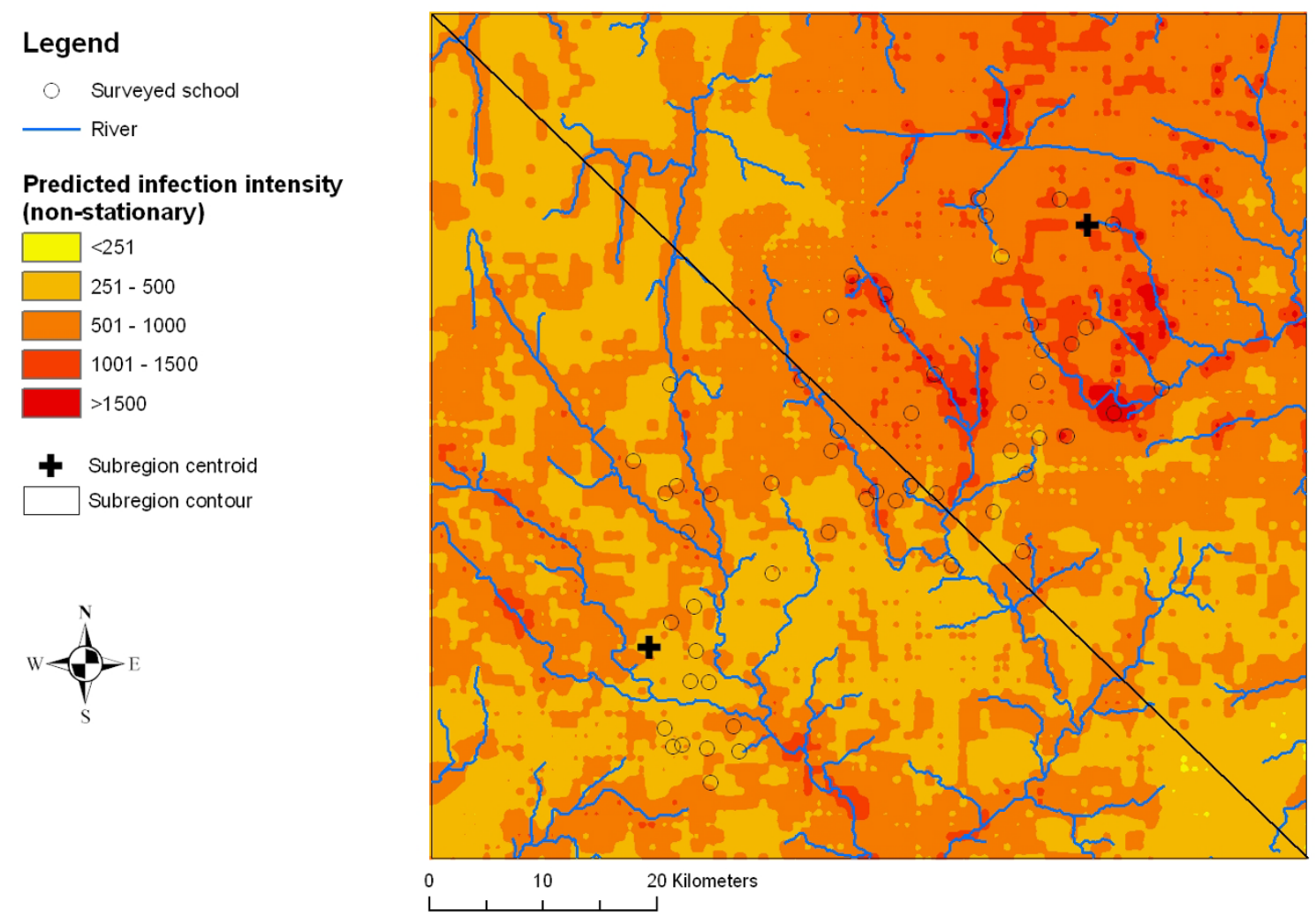

\section{Figure 6 \\ Smoothed map of $P$. falciparum parasitaemia derived from a non-stationary negative binomial regression model with fixed subregions using Bayesian kriging in the region of Man, western Côte d'Ivoire.}

tionary model with fixed subregions, this covariate was not significant. Instead, distance to rivers appeared as a significant covariate in the non-stationary model with fixed subregions. Such differing results have also been reported by others when comparing stationary and nonstationary models for the risk of malaria across Mali [9]. The covariate mean RFE during the main malaria transmission season had the lower BCIs near 1 in both stationary and non-stationary models with ecological subregions, and the increase in odds due to increased rainfall was only 0.28 and 0.24 , respectively. In contrast, the non-stationary model with fixed subregions seems particularly promising, as the upper $\mathrm{BCI}$ for the covariate distance to rivers was not close to 1 and the parasitaemia risk decreased by over a third with increasing distance from rivers.

Employing a spatially-explicit risk profiling approach, demographic, environmental and socioeconomic risk factors were identified that govern the geographic distribution of $P$. falciparum parasitaemia in a high endemicity area at the district level. This information can be utilized for designing and implementing malaria control interventions. In particular, at the time of the study in 2001/2002, virtually no malaria control interventions were carried out in the region of Man. The very low frequency of schoolchildren reported sleeping under a bed net $(<10 \%)$ documents this issue [19]. Although bed nets were available for purchase from local dispensaries and the district hospital in the town of Man, the price was perceived as too high. It is speculated that the malaria situation in this region has not improved, partially explained by an armed conflict starting in September 2002 that also hit the region of Man and resulted in a collapse of the health care delivery systems $[41,42]$. Available information supports this claim; coverage of bed nets (ITNs) was reported below 5\% in Côte d'Ivoire at a national scale [43] and in the Man region in particular [44]. The results further suggest that health-seeking regarding prevention and treatment of malaria at dispensaries was weak, as no statistical significance was found with regards to distance to a health post.

\section{Conclusion}

A massive scale-up of bed net coverage in the region of Man, ideally promoting LLINs is indicated. Villages located in the north-eastern part of the study area and those in close proximity to rivers should be targeted first to have the strongest impact. Once control interventions 


\section{Legend}

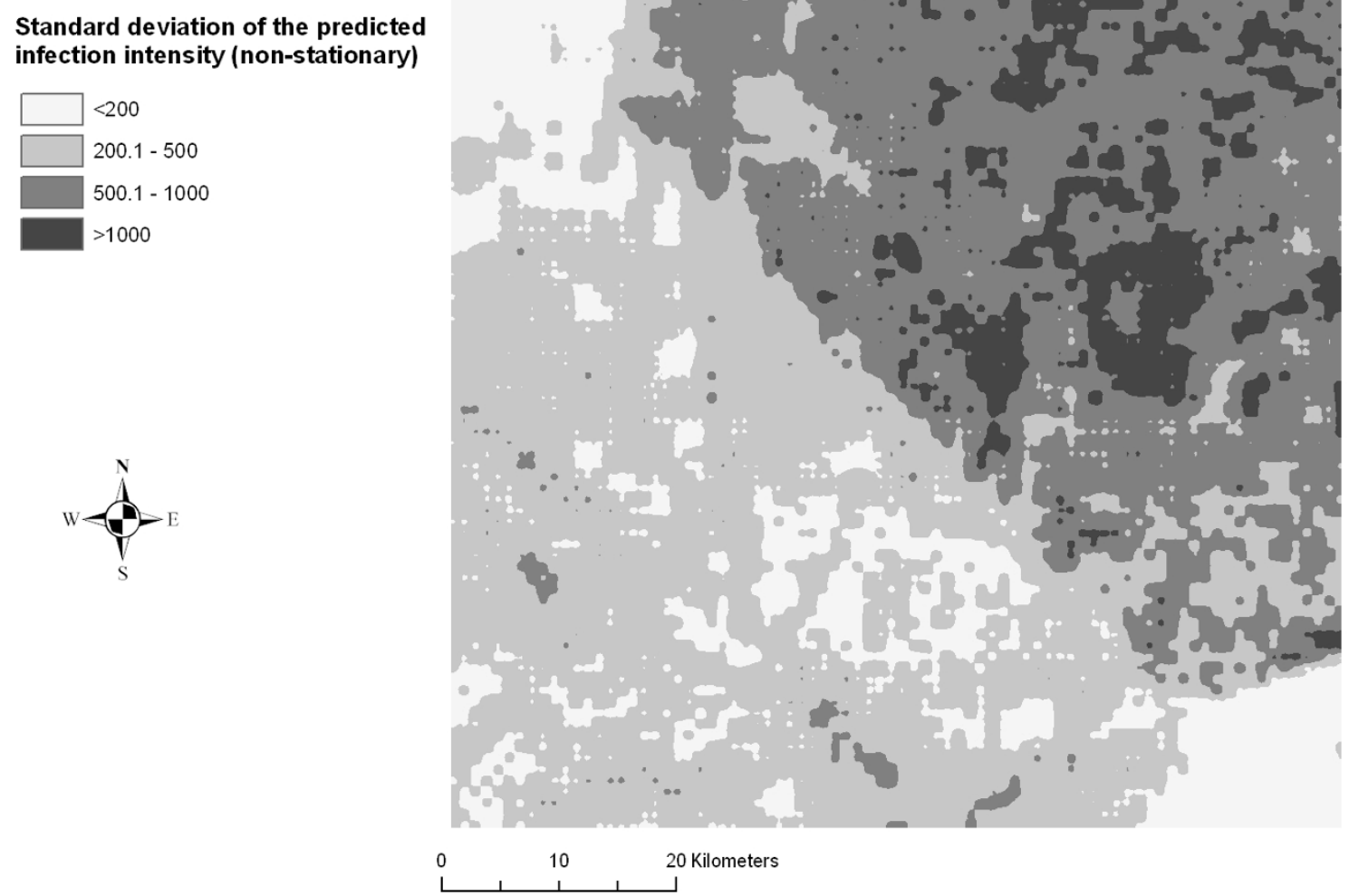

\section{Figure 7}

Standard deviation of the predicted $P$. falciparum parasitaemia derived from a non-stationary negative binomial regression model with fixed subregions using Bayesian kriging in the region of Man, western Côte d'Ivoire.

will start to take off, it is conceivable that the malaria situation will become more heterogeneous across the Man region, and hence stationarity in modeling prevalence and parasitaemia will no longer be justified, as control interventions are likely to vary depending on location. Future field studies will elucidate whether the presented integrated risk profiling and control approach can also be employed for rigorous monitoring and performance evaluations of the district-level malaria control programme.

\section{List of abbreviations}

ACT: Artemisinin-based Combination Therapy; ADDS: Africa Data Dissemination Service; AIC: Akaike Information Criterion; BCI: Bayesian Credible Interval; CI: Confidence Interval; DALYs: Disability-Adjusted Life Years; DEM: Digital Elevation Model; DIC: Deviance Information Criterion; GIS: Geographical Information system; GPS: Global Positioning System; ITN: Insecticide-Treated Nets; LLINs: Long-Lasting Insecticidal Nets; LST: Land Surface Temperature; MCMC: Markov Chain Monte Carlo; MODIS: Moderate Resolution Imaging Spectroradiometer; NDVI: Normalized Difference Vegetation Index; RFE:
Rainfall Estimates; SRTM: Shuttle Radar Topography Mission.

\section{Competing interests}

The authors declare that they have no competing interests.

\section{Authors' contributions}

GR contributed to the conception and design, participated in the data collection, carried out the spatial analyses and interpretation of the data and drafted the manuscript. KDS was involved in the data collection, quality control, data analyses and drafting of the manuscript. PV contributed to the analysis of the data and drafting of the manuscript. BHS was involved in the interpretation of the data and critical revision of the manuscript. AY was involved in the acquisition of data. MT contributed to the conception and design. JU contributed to the conception and design, interpretation of the data and drafting of the manuscript. EKN was involved in the conception and design as well as the critical revision of the manuscript. All authors read and approved the initial submission and the revised version of the manuscript. 


\section{Acknowledgements}

We thank the staff members of the health and sanitation district of the region of Man, the education officers, directors, teachers, schoolchildren and the field and laboratory technicians (M. Traoré, K.L. Lohourignon, B.A Sosthène, $A$. Allangba and $S$. Diabaté). This investigation received financial support from the Swiss National Science Foundation to P. Vounatsou (project no. 3252B0-102/36/I) and J. Utzinger (project no. PPOOB-102883 and PPOOB-I 19129), and the University of Queensland to G. Raso through a Postdoctoral Research Fellowship and Early Career Research Grant (project no. 2007002086). E.K. N'Goran is grateful to Fairmed for financial support.

\section{References}

I. Hay SI, Guerra CA, Gething PW, Patil AP, Tatem AJ, Noor AM, Kabaria CW, Manh BH, Elyazar IRF, Brooker S, Smith DL, Moyeed RA, Snow RW: A world malaria map: Plasmodium falciparum endemicity in 2007. PLoS Med 2009, 6:e 1000048.

2. Sachs J, Malaney P: The economic and social burden of malaria. Nature 2002, 4I 5:680-685.

3. Snow RW, Guerra CA, Noor AM, Myint HY, Hay SI: The global distribution of clinical episodes of Plasmodium falciparum malaria. Nature 2005, 434:214-2I7.

4. Lopez AD, Mathers CD, Ezzati M, Jamison DT, Murray CJL: Global and regional burden of disease and risk factors, $200 \mathrm{I}$ : systematic analysis of population health data. Lancet 2006, 367:1747-1757.

5. Gomez Sambo L: Defining and defeating the intolerable burden of malaria III. Progress and perspectives. Am J Trop Med Hyg 2007, 77(Suppl 6):iii.

6. Bouvier P, Rougemont A, Breslow N, Doumbo O, Delley V, Dicko A, Diakite $M$, Mauris A, Robert CF: Seasonality and malaria in a West African village: does high parasite density predict fever incidence? Am J Epidemiol 1997, I 45:850-857.

7. Craig MH, Snow RW, le Sueur D: A climate-based distribution model of malaria transmission in sub-Saharan Africa. Parasitol Today 1999, I5:105-III.

8. Graves PM, Osgood DE, Thomson MC, Sereke K, Araia A, Zerom M, Ceccato P, Bell M, Del Corral J, Ghebreselassie S, Brantly EP, Ghebremeskel T: Effectiveness of malaria control during changing climate conditions in Eritrea, 1998-2003. Trop Med Int Health 2008, I3:218-228.

9. Gosoniu L, Vounatsou P, Sogoba N, Smith T: Bayesian modelling of geostatistical malaria risk data. Geospat Health 2006, I:I27-139.

10. Patz JA, Strzepek K, Lele S, Hedden M, Greene S, Noden B, Hay SI, Kalkstein L, Beier JC: Predicting key malaria transmission factors, biting and entomological inoculation rates, using modelled soil moisture in Kenya. Trop Med Int Health 1998, 3:818-827.

II. Snow RW, Gouws E, Omumbo J, Rapuoda B, Craig MH, Tanser FC, le Sueur D, Ouma J: Models to predict the intensity of Plasmodium falciparum transmission: applications to the burden of disease in Kenya. Trans R Soc Trop Med Hyg 1998, 92:60 I-606.

12. Brooker S, Leslie T, Kolaczinski K, Mohsen E, Mehboob N, Saleheen S, Khudonazarov J, Freeman T, Clements A, Rowland M, Kolaczinski J: Spatial epidemiology of Plasmodium vivax, Afghanistan. Emerg Infect Dis 2006, I2:1600-1602.

13. Cressie N: Regional mapping of incidence rates using spatial Bayesian models. Med Care 1993, 3 I (Suppl 5):60-65.

14. Gosoniu L, Vounatsou P, Sogoba N, Maire N, Smith T: Mapping malaria risk in West Africa using a Bayesian nonparametric non-stationary model. Comput Stat Data Anal 2009, 53:3358-337I.

15. Silué KD, Raso G, Yapi A, Vounatsou P, Tanner M, N'Goran EK, Utzinger J: Spatially-explicit risk profiling of Plasmodium falciparum infections at a small scale: a geostatistical modelling approach. Malar J 2008, 7: I II.

16. Keiser J, Singer $\mathrm{BH}$, Utzinger J: Reducing the burden of malaria in different eco-epidemiological settings with environmental management: a systematic review. Lancet Infect Dis 2005, 5:695-708.

17. Utzinger J, N'Goran EK, N'Dri A, Lengeler C, Xiao SH, Tanner M: Oral artemether for prevention of Schistosoma mansoni infection: randomised controlled trial. Lancet 2000, 355:1320-1325.

18. Raso G, Luginbühl A, Adjoua CA, Tian-Bi NT, Silue KD, Matthys B, Vounatsou P, Wang Y, Dumas ME, Holmes E, Singer BH, Tanner M, N'Goran EK, Utzinger J: Multiple parasite infections and their relationship to self-reported morbidity indicators in a community of rural Côte d'Ivoire. Int J Epidemiol 2004, 33: I 092-I 102.

19. Raso G, Utzinger J, Silué KD, Ouattara M, Yapi A, Toty A, Matthys B, Vounatsou $P$, Tanner $M, N$ 'Goran EK: Disparities in parasitic infections, perceived ill health and access to health care among poorer and less poor schoolchildren of rural Côte d'Ivoire. Trop Med Int Health 2005, 1 0:42-57.

20. Matthys B, N'Goran EK, Kone M, Koudou BG, Vounatsou P, Cisse G, Tschannen $A B$, Tanner $M$, Utzinger J: Urban agricultural land use and characterization of mosquito larval habitats in a medium-sized town of Côte d'Ivoire. J Vector Ecol 2006, 31:319-333.

21. Matthys B, Vounatsou P, Raso G, Tschannen AB, Becket EG, Gosoniu L, Cisse G, Tanner M, N'Goran EK, Utzinger J: Urban farming and malaria risk factors in a medium-sized town in Côte d'Ivoire. Am J Trop Med Hyg 2006, 75:1223-1231.

22. Raso G, Matthys B, N'Goran EK, Tanner M, Vounatsou P, Utzinger J: Spatial risk prediction and mapping of Schistosoma mansoni infections among schoolchildren living in western Côte d'Ivoire. Parasitology 2005, I 3 I:97-108.

23. Beck-Wörner C, Raso G, Vounatsou P, N'Goran EK, Rigo G, Parlow E, Utzinger J: Bayesian spatial risk prediction of Schistosoma mansoni infection in western Côte d'Ivoire using a remotelysensed digital elevation model. Am J Trop Med Hyg 2007, 76:956-963.

24. Gelfand AE, Smith AFM: Sampling-based approaches to calculating marginal densities. J Am Stat Assoc 1990, 85:398-4I0.

25. Diggle PJ, Tawn JA, Moyeed RA: Model-based geostatistics. J Roy Stat Soc C-App 1998, 47:299-326.

26. Banerjee S, Gelfand AE, Knight JR, Sirmans CF: Spatial modeling of house prices using normalized distance-weighted sum of stationary processes. J Bus Econ Stat 2004, 22:206-213.

27. Spiegelhalter DJ, Best N, Charlin BP, Linde A van der: Bayesian measures of model complexity and fit. J Roy Stat Soc, Ser B 2002, 64:583-639.

28. Greenwood BM, Fidock DA, Kyle DE, Kappe SH, Alonso PL, Collins $\mathrm{FH}$, Duffy PE: Malaria: progress, perils, and prospects for eradication. J Clin Invest 2008, I I 8: I 266- I 276.

29. Raso G, Vounatsou P, Singer BH, N'Goran EK, Tanner M, Utzinger J: An integrated approach for risk profiling and spatial prediction of Schistosoma mansoni-hookworm coinfection. Proc Nat Acad Sci USA 2006, 103:6934-6939.

30. Gupta S, Snow RW, Donnelly CA, Marsh K, Newbold C: Immunity to non-cerebral severe malaria is acquired after one or two infections. Nat Med 1999, 5:340-343.

31. Grobusch MP, Kremsner PG: Uncomplicated malaria. Curr Top Microbiol Immunol 2005, 295:83-104.

32. Delley V, Bouvier P, Breslow N, Doumbo O, Sagara I, Diakite M, Mauris $A$, Dolo $A$, Rougemont $A$ : What does a single determination of malaria parasite density mean? A longitudinal survey in Mali. Trop Med Int Health 2000, 5:404-4I 2.

33. Coleman RE, Sattabongkot J, Promstaporm S, Maneechai N, Tippayachai B, Kengluecha A, Rachapaew N, Zollner G, Miller RS, Vaughan JA, Thimasarn K, Khuntirat B: Comparison of PCR and microscopy for the detection of asymptomatic malaria in a Plasmodium falciparum/vivax endemic area in Thailand. Malar J 2006, 5:121.

34. Menge DM, Ernst KC, Vulule JM, Zimmerman PA, Guo H, John CC: Microscopy underestimates the frequency of Plasmodium falciparum infection in symptomatic individuals in a low transmission highland area. Am J Trop Med Hyg 2008, 79: I73-I77.

35. Armstrong Schellenberg J, Victora CG, Mushi A, de Savigny D, Schellenberg $D$, Mshinda $H$, Bryce J: Inequities among the very poor: health care for children in rural southern Tanzania. Lancet 2003, 36 I:56I-566.

36. Raso G, Vounatsou P, Gosoniu L, Tanner M, N'Goran EK, Utzinger J: Risk factors and spatial patterns of hookworm infection among schoolchildren in a rural area of western Côte d'Ivoire. Int J Parasitol 2006, 36:201-210.

37. Briet OJ, Dossou-Yovo J, Akodo E, van de Giesen N, Teuscher TM: The relationship between Anopheles gambiae density and 
rice cultivation in the savannah zone and forest zone of Côte d'Ivoire. Trop Med Int Health 2003, 8:439-448.

38. Koudou BG, Tano Y, Doumbia M, Nsanzabana C, Cisse G, Girardin O, Dao D, N'Goran EK, Vounatsou P, Bordmann G, Keiser J, Tanner $M$, Utzinger J: Malaria transmission dynamics in central Côte d'Ivoire: the influence of changing patterns of irrigated rice agriculture. Med Vet Entomol 2005, 19:27-37.

39. Costantini C, Li SG, Della Torre A, Sagnon N, Coluzzi M, Taylor CE: Density, survival and dispersal of Anopheles gambiae complex mosquitoes in a West African Sudan savanna village. Med Vet Entomol 1996, 10:203-219.

40. Cohen JM, Ernst KC, Lindblade KA, Vulule JM, John CC, Wilson ML: Topography-derived wetness indices are associated with household-level malaria risk in two communities in the western Kenyan highlands. Malar / 2008, 7:40.

4I. Betsi NA, Koudou BG, Cisse G, Tschannen AB, Pignol AM, Ouattara $Y$, Madougou Z, Tanner M, Utzinger J: Effect of an armed conflict on human resources and health systems in Côte d'Ivoire: prevention of and care for people with HIVIAIDS. AIDS Care 2006, 18:356-365.

42. Fürst $T$, Raso G, Acka CA, Tschannen AB, N'Goran EK, Utzinger J: Dynamics of socioeconomic risk factors for neglected tropical diseases and malaria in an armed conflict. PLOS NTDs 2009, 3:e513.

43. Noor AM, Mutheu JJ, Tatem AJ, Hay SI, Snow RW: Insecticidetreated net coverage in Africa: mapping progress in 2000-07. Lancet 2009, 373:58-67.

44. UNICEF: The State of the World's Children 2007. In The double dividend of gender equality New York: The United Nations Children's Fund (UNICEF); 2007:160.
Publish with Bio Med Central and every scientist can read your work free of charge

"BioMed Central will be the most significant development for disseminating the results of biomedical research in our lifetime. "

Sir Paul Nurse, Cancer Research UK

Your research papers will be:

- available free of charge to the entire biomedical community

- peer reviewed and published immediately upon acceptance

- cited in PubMed and archived on PubMed Central

- yours - you keep the copyright

Submit your manuscript here:

http://www.biomedcentral.com/info/publishing_adv.asp
BioMedcentral 